\title{
“Nós somos os primeiros a serem acusados": um estudo sobre o "anticiganismo" e as permanências coloniais no direito brasileiro
}

\author{
"We are the first to be accused": a study on \\ "antigypsysim" and colonial permanences in brazilian \\ law
}

iD Phillipe Cupertino Salloum e Silva ${ }^{1}$

(9) Dr. Luiz Eduardo Figueira²

Resumo: Nos últimos anos, as narrativas sobre as condições de vida da "população cigana"³ brasileira, associadas à exclusão social, preconceitos e discriminação racial, vêm provocando e atraindo uma série de atores, individuais e coletivos, assim como órgãos da burocracia estatal, a pensar e intervir nesta realidade. O presente artigo busca compreender de que forma as leis e as políticas do período colonial foram mobilizadas e como hoje podem repercutir na construção da condição jurídico-política dos "ciganos" no Brasil. Foi realizado, a partir de fontes primárias e secundárias, um estudo genealógico, sobre como a presença das pessoas que se identificavam e que eram identificadas como "ciganas" foram geridas no território brasileiro, durante o período da colonização portu-

\footnotetext{
1 Doutor em Direito pela Universidade Federal do Rio de Janeiro, onde integra o grupo de pesquisa "Luta por direitos e justiça e práticas estatais: uma perspectiva etnográfica". Mestre em Ciências Jurídicas pela Universidade Federal da Paraíba (2015). Bacharel em Direito pela Universidade Estadual de Santa Cruz (2013). Iniciou pesquisa de Pós-Doutorado no Departamento de Antropología Social, linha de pesquisa Antropología y Minorías étnicas, da Universidad Complutense de Madrid (2021-2022). Professor de Direito da Universidade Estadual de Goiás (Campus Norte). Advogado especialista em Direitos Humanos.

2 Professor Associado da Faculdade Nacional de Direito da Universidade Federal do Rio de Janeiro, desenvolvendo suas atividades nos cursos de graduação, mestrado e doutorado em Direito - PPGD. Coordena o Núcleo de Cultura Jurídica, grupo que reúne pesquisadores de diferentes instituições e níveis de formação. Possui graduação em Direito pela Pontifícia Universidade Católica do Rio de Janeiro (1995), é mestre (2000) e doutor (2007) em Antropologia pela Universidade Federal Fluminense.

3 As aspas duplas são adotadas para destacar conceitos que, por acionarem significações nesta pesquisa, merecem definições contextualizadas.
} 
guesa. A análise e o levantamento sobre as políticas e leis "anticiganas", realizados neste estudo, não são necessariamente cronológicos, tão pouco contemplam a totalidade das medidas existentes voltadas para a gestão dos "povos ciganos" no Brasil. Além da investigação documental e bibliográfica, este estudo integrou a pesquisa de campo a observação direta e participante dos autores, em atividades em que os "povos ciganos" atuam no âmbito da burocracia estatal, especialmente a tramitação do Projeto de Lei do Senado $n^{\circ}$ 248/2015, que pretende criar o “Estatuto Cigano". Há uma rede de práticas e significados sobre a condição "cigana" que vêm sendo tecidos desde o passado, conectados ao presente, a partir de novas bases, que se optou por analisar neste estudo.

Palavras-chave: Povos ciganos. Antropologia Jurídica. História do Direito. Colonialidade.

\begin{abstract}
In recent years, the narratives about living conditions of the Brazilians Gypsies People, associated with social exclusion, prejudices and racial discrimination, have been provoking and attracting a series of actors, individual and collective, as well as organs of the state bureaucracy, to think and intervene in this. reality. This article seeks to understand how the laws and policies of the colonial period were mobilized and how they can have an impact on the construction of the legal and political condition of "gypsies" in Brazil. A genealogical study was carried out, from primary and secondary sources, on how the presence of "gypsies" people were managed in Brazilian territory, during the period of Portuguese colonization. The analysis and data survey of "anti-Gypsy" policies and laws, carried out in this study, are not necessarily chronological, nor do they contemplate the totality of existing measures aimed at the management of "Gypsy people" in Brazil. In addition to the documentary and bibliographic investigation, this study integrated field research with the direct and participant observation of the authors, in activities in which the "Gypsy people" act within the scope of the state bureaucracy, especially the processing of the Bill 248/2015, which intends to create the "Gypsy Statute". There is a network of practices and meanings about the
\end{abstract}


"gypsy" condition that have been woven since the past, connected to the present, from new bases, which we chose to analyze in this study.

Keywords: Gypsies people. Coloniality. Legal Anthropology. History of Law.

Data de submissão do artigo:

Data de aceite do artigo: 
"Nós somos os primeiros a serem acusados": um estudo sobre o "anticiganismo" e as... Phillipe Cupertino Salloum e Silva • Dr. Luiz Eduardo Figueira

\section{Introdução}

Há mais de quatrocentos anos vivendo no território hoje chamado Brasil, os "povos ciganos" vêm contribuindo, embora não de forma harmônica e festiva, para a fundação social, cultural e econômica deste país. As constantes expulsões, episódios de violências, diásporas, e o nomadismo (forçado) são elementos marcantes nas narrativas dessas pessoas que se identificam e são identificadas como "ciganas", tanto sobre o passado, como sobre o presente.

Nos últimos anos, as narrativas sobre as condições de vida da população "cigana" brasileira, que ainda permanecem associadas à exclusão social, violências, preconceitos e discriminação racial, vêm provocando e atraindo uma série de atores, individuais e coletivos, assim como órgãos da burocracia estatal, a pensar e intervir nesta realidade. São as conferências, plenárias, audiências públicas, reuniões institucionais que passam a fazer parte da rotina de interlocução e espaços de diálogos entre o Estado e os "povos ciganos".

Embora as informações sobre os "ciganos" no Brasil sejam imprecisas e ainda permaneça uma certa invisibilidade, já há um processo de reconhecimento, no sentido de formalização institucional, intensificado a partir do ano 2005, que se tratam de populações tradicionais, de presença expressiva no território nacional e, que, ao mesmo tempo, reivindicam direitos e ações concretas por meio de políticas públicas.

O objetivo deste artigo é compreender de que forma as leis e as políticas do período colonial foram mobilizadas e como hoje podem repercutir na construção da condição jurídico-política dos "ciganos" no Brasil. Foi realizado, a partir de fontes primárias e secundárias, um estudo genealógico, com inspiração no método arqueológico de Michel Foucault (2012), sobre como a presença das pessoas que se identificavam e que eram identificadas como "ciganas" foram geridas no território brasileiro, desde o período da colonização portuguesa. A análise e o levantamento sobre as 
"Nós somos os primeiros a serem acusados": um estudo sobre o "anticiganismo" e as... Phillipe Cupertino Salloum e Silva • Dr. Luiz Eduardo Figueira

políticas e leis "anticiganas" realizados neste estudo não são necessariamente cronológicos, tão pouco contemplam a totalidade das medidas existentes voltadas para a gestão dos "povos ciganos" no Brasil.

A presente pesquisa leva também em conta as interações dos "povos ciganos" nos espaços da burocracia estatal e com os atores institucionais, especialmente no âmbito da tramitação do Projeto de Lei do Senado n²48/2015, que pretende criar o "Estatuto Cigano". Há uma rede de práticas e significados sobre a condição "cigana" que vêm sendo tecidos desde o passado, conectados ao presente, a partir de novas bases, que se optou por analisar neste estudo.

Em pronunciamentos oficiais, por parte de atores institucionais, em textos acadêmicos ou nos meios de comunicação, são recorrentes os argumentos que atribuem carga valorativa que contribuem, direta ou indiretamente, para a delimitação das identidades "ciganas". Esse conjunto simbólico produz sentidos ambíguos, seja por pregar a imutabilidade da identidade "cigana" e dos estigmas negativos, seja por remeter a esforços que buscam promover assimilações e uma suposta integração social, mediante mudanças culturais e negação da identidade, no sentido de pertencimento étnico.

A invocação do termo "cigano", nas últimas décadas, especialmente a partir da década de 1980, vem produzindo efeitos de poder diferentes. Ao mesmo tempo que invoca significação dos Direitos Humanos, a própria existência de um regime nacional e internacional de proteção às minorias étnicas, como os "ciganos", está relacionado às permanências das classificações raciais e, consequentemente, dos estigmas que fomentam controles e exclusão das populações reconhecidas como "ciganas". Mas o que querem dizer com isso? Haveria um deslocamento semântico entre o que é "ser cigano" no âmbito dos Direitos Humanos e o que é "ser cigano" na esfera do Sistema de Justiça Penal, nas demais práticas concretas estatais e da sociedade como um todo? 
"Nós somos os primeiros a serem acusados": um estudo sobre o "anticiganismo" e as... Phillipe Cupertino Salloum e Silva • Dr. Luiz Eduardo Figueira

Ao acompanhar, descrever e analisar a tramitação do PLS $n^{\circ}$ 248/2015, assim como outros espaços políticos institucionais em que são negociados direitos pelos e para os "ciganos", notou-se algumas práticas na esfera institucional que apontam para as permanências de "práticas coloniais", e partir desses estranhamentos foram empenhados esforços para realizar este estudo genealógico.

Integrou a pesquisa de campo a observação direta e participante: a) da audiência pública realizada pelo MPF no município de Patos, interior da Paraíba, no dia 29 de maio de 2017; b) da audiência pública realizada no auditório da Procuradoria-Geral da República (PGR), na noite do dia 27 de maio de 2018, que discutiu de forma mais geral os direitos dos ciganos e a delimitação de políticas públicas para esta população; c) da audiência pública realizada na Comissão de Direitos Humanos do Senado Federal, na manhã do dia 28 de maio de 2018 de 2018, momento em que foi discutido diretamente sobre o conteúdo do projeto de lei; d) da IV Conferência Nacional da Promoção da Igualdade Racial (CONAPIR), que ocorreu entre 27 e 30 de maio de 2018; e) da segunda reunião ordinária do Conselho Nacional dos Povos e Comunidades Tradicionais (CNPCT), nos dias 7 e 8 de dezembro de 2018; assim como demais interações e contribuições técnicas que o autor deste artigo realiza com assessores parlamentares que trabalham em torno do conteúdo do projeto de lei.

O ser "cigano", como direito, pode ser uma lente para estudar como as práticas estatais explicitam a forma de administração da vida desses sujeitos. O reconhecimento da condição "cigana", enquanto população tradicional brasileira, vem possibilitando o acesso a outros direitos e políticas públicas. Ademais, este artigo pretende visibilizar a existência de "ciganos" organizados, assim como demais estruturas e órgãos acionados, sujeitos que pleiteiam reconhecimento da sociedade e Estado, assim como lutam pelo direito de existência como um segmento social que é culturalmente diferenciado dos demais brasileiros. 
"Nós somos os primeiros a serem acusados": um estudo sobre o "anticiganismo" e as... Phillipe Cupertino Salloum e Silva • Dr. Luiz Eduardo Figueira

\section{O "Salvo-Conduto"}

No início da audiência pública realizada no auditório da PGR em 27 de maio de 2018, foi exibido um breve vídeo, editado pela comunicação do Ministério Público Federal (MPF), que narra o histórico da atuação do órgão em face da condição dos "ciganos" no Brasil. Além de servidores do MPF, este evento reuniu pessoas "ciganas", apoiadores da causa, assim como representantes de diferentes órgãos públicos do governo. O material exibido inicia afirmando que "há 20 anos o Ministério Público Federal expediu o primeiro salvo-conduto para que um cigano que sempre era detido pudesse transitar livremente" (TV MPF: 2018; destaque do autor).

Em outra audiência pública do MPF, no município de Patos, interior da Paraíba, em 2017, foi também feito referência à primeira aplicação deste instituto, por um membro do MPF, para garantir o direito de locomoção de uma pessoa "cigana", que utilizou o "salvo-conduto" para entrar no estado da Paraíba (MPF, 2017).

Há pouco mais de 20 anos, essa foi a primeira versão de salvo conduto expedido por um membro do Ministério Público Federal na Paraíba (MPF/PB) para que um cigano, que sempre era abordado e detido pela polícia na fronteira entre os estados da Paraíba e Pernambuco, pudesse transitar livremente e exercer suas atividades comerciais. (MPF, 2017).

A primeira impressão que os autores tiveram é que este documento, o "salvo-conduto", seria uma espécie de carta de recomendação, emitida por uma autoridade, atestando a boa procedência de determinadas pessoas, no caso "ciganas", para que pudessem circular no espaço. Franz Moonen, autor central para aqui traçar uma genealogia da condição "cigana" no Brasil, assim como outros estudiosos, expõem uma série de registros do uso "salvo-condu-

4 Este evento foi organizado pelo Ministério Público Federal, em alusão ao “Dia Nacional do Cigano”, que passou a ser comemorado, oficialmente, a partir do ano de 2007, no dia 24 de maio. 
"Nós somos os primeiros a serem acusados": um estudo sobre o "anticiganismo" e as... Phillipe Cupertino Salloum e Silva • Dr. Luiz Eduardo Figueira

tos", a partir do século XV, fornecidos por reis, imperadores ou papas, documentos que foram usados por grupos que, posteriormente, foram classificados como "ciganos", na Europa.

É importante ressaltar que "cigano" é uma classificação externa, inicialmente, atribuída por outras pessoas. Além disso, trata-se de um povo, em geral, de cultura ágrafa, isto é, que não registra por escrito suas memórias e histórias. Dessa forma, optouse, no primeiro tópico, por iniciar a genealogia da condição jurídica política dos "ciganos" no Brasil a partir da reflexão sobre o episódio do "salvo-conduto", narrado no vídeo do MPF que foi apresentado na audiência pública, para, posteriormente, no segundo tópico, tratar das leis coloniais produzidas ao longo dos séculos visando às populações reconhecidas como "ciganas". Os "salvo-condutos", concedidos pelas autoridades integrantes das classes dominantes de cada época, antecedem as próprias leis "anticiganas".

Segue, abaixo, dois diferentes autores que fazem referência ao uso de "salvo-condutos" como uma das primeiras estratégias mobilizadas pelas populações posteriormente classificadas como "ciganas" para negociar a presença, a aceitação pelo outro, assim como a possibilidade de poder circular entre territórios.

[...] veio do Leste um grande número de indivíduos errantes (cerca de 300), antes nunca vistos. (...) viajavam em bandos e pernoitavam fora das cidades, ao ar livre; eram feios, pretos como os Tártaros e se chamavam Secani. [...] portavam salvocondutos fornecidos por reis [...] Apresentavam-se como penitentes ou peregrinos, com cartas de apresentação e salvo-condutos de reis, príncipes e nobres, e até do papa. (MOONEN, 2011, p. 24-26).

Sigismund, Rei da Hungria, Boêmia e outros reinos haviam dado uma carta de salvo conduto para um dos primeiros grupos de ciganos que entraram na Europa Ocidental no século XV. Esta carta com o salvo-conduto está datada em 1423. (WAGNER, 1987, p. 33).

Segundo Angus Fraser (1992), os "ciganos" aprenderam o valor do "salvo-conduto" observando peregrinos e viajantes europeus 
"Nós somos os primeiros a serem acusados": um estudo sobre o "anticiganismo" e as... Phillipe Cupertino Salloum e Silva • Dr. Luiz Eduardo Figueira

nos portos de Constantinopla ou na Grécia, durante o século XIII e XIV, e resolveram imitar este exemplo para obter uma fonte de renda fácil quando decidiram migrar para a Europa Ocidental. Séculos depois, no Brasil, o MPF relata o uso deste instituto, na década de 1990, pelo órgão, para garantir a circulação de um determinado "cigano", não deixando claro, na ocasião, se o "salvo-conduto" foi usado outras vezes.

No Brasil, o decreto $n^{\circ} 1.983$, de 14 de agosto de 1996, prevê que "salvo-conduto" é o documento de "viagem, de propriedade da União, expedido pelo Ministério da Justiça, destinado a permitir a saída do território nacional de todo aquele que obtenha asilo diplomático concedido por governo estrangeiro" (BRASIL, 1996). O Decreto $n^{\circ} 5.978$, de 4 de dezembro de 2006, também faz referência ao "salvo-conduto" no art. 10, inciso IV, como um documento de viagem para pessoas estrangeiras (BRASIL, 2006). Não há outras referências a este instituto no ordenamento interno brasileiro.

Por que determinadas pessoas precisam apresentar "salvo-condutos" para circular dentro do território nacional? Qual a razão para a aplicação do instituto do "salvo-conduto" para pessoas "ciganas", que são também brasileiras? Será que todos "ciganos" que precisaram tiveram acesso ao tal "salvo-conduto"? Quais os critérios para conseguir um "salvo-conduto"? Essas indagações foram centrais para delinear o esforço genealógico realizado neste artigo, a fim de compreender a construção político-jurídica da condição do "cigana" no Brasil.

Não há previsão expressa na legislação brasileira para a concessão de "salvo-condutos" para que pessoas brasileiras possam circular internamente no território nacional. Todavia, o propósito desta problematização não é averiguar ou apontar uma suposta irregularidade (ou ilegalidade) na aplicação do "salvo-conduto".

Inseridas nas relações de forças que atuam as mais diversas autoridades brasileiras, considera-se a aplicação do "salvo-conduto" como uma estratégia do MPF para que se garantisse o direito de ir e vir da pessoa que se identificava e era identificada como 
"Nós somos os primeiros a serem acusados": um estudo sobre o "anticiganismo" e as... Phillipe Cupertino Salloum e Silva • Dr. Luiz Eduardo Figueira

"cigana". A principal dúvida que permanece é se essa política do "salvo-conduto" alcançava a todos "ciganos" que se encontrava na mesma situação ao caso relatado na audiência pública. Por outro lado, é possível afirmar que a aplicação do "salvo-conduto" às pessoas "ciganas" dá-se, justamente, nas dobras, nas margens entre o formal e o informal, num campo de forças disputadas a partir do MPF, dentro dele, como também através de outros órgãos.

As dobras, as margens, que não são visíveis ou materiais, derivam de um conjunto de condutas, que podem ou não estarem positivadas. Há uma fronteira instável, porosa entre o positivado e o não positivado, o formal e o informal, que envolvem as relações de poderes e os campos de forças. O Estado é sempre um projeto incompleto, que deve ser constantemente enunciado e imaginado, que invoca os limites do fora, do lugar do selvagem, do vazio e do caos (DAS; POOLE, 2008). Deste modo, é preciso pensar menos em fronteiras como espaços limites e periféricos ao poder central e mais como margens que se multiplicam e se deslocam tanto na periferia quanto no centro.

Recorda-se que, durante a audiência pública que os autores acompanharam, em março de 2017, no município paraibano de Patos, o então Vice Procurador Geral da República, Luciano Mariz Maia, afirmou que o "cigano" destinatário do "salvo conduto" questionou se as "autoridades" iriam acreditar na autenticidade do documento. Como resposta, em forma de garantia, o procurador disse para quem duvidasse da autenticidade do documento, que ligasse para ele, e por isso concedeu o seu contato de telefone caso fosse necessário.

Ao analisar a tramitação do PLS n $248 / 2015$, no Congresso Nacional, e a luta, em geral, dos "povos ciganos" por direitos, no Brasil, é possível afirmar que alguns atores sociais do MPF vêm atuando como um dos principais interlocutores dos "ciganos" com o Estado brasileiro. O MPF é convidado a se manifestar, e vem acompanhando os debates em torno da aprovação do projeto de lei "Estatuto do Cigano", desde o início da tramitação. Este convite ao órgão, em si, não está previsto no regimento interno do Senado, 
"Nós somos os primeiros a serem acusados": um estudo sobre o "anticiganismo" e as... Phillipe Cupertino Salloum e Silva • Dr. Luiz Eduardo Figueira

decorre das relações de forças em que a instituição e seus atores possuem notório reconhecimento entre aqueles que trabalham com os "ciganos".

O pacto social, proposto pela atual Constituição Federal de 1988, ao atribuir enquanto função do Ministério Público "defender judicialmente os direitos e interesses das populações indígenas" (artigo 129, inciso V), contribuiu para a incorporação da Lei Complementar $n^{\circ} 75$, de 20 de maio de 1993, que estendeu às atribuições do Ministério Público Federal para também incentivar e fiscalizar o Estado, assim como a sociedade, na defesa dos interesses das minorias étnicas (art. 6, VII, “" ${ }^{\prime \prime}$ ), em busca da concretização dos direitos culturais.

Portanto, antes da criação de um órgão público, no âmbito do Poder Executivo, com objetivo específico de trabalhar com as relações étnica-raciais no Brasil, como é o caso da Secretaria Especial de Promoção da Igualdade Racial, o Ministério Público Federal, a partir da década de 1990, começou a atuar em torno desta temática, fiscalizando e ao mesmo tempo estimulando as ações do Estado na promoção de políticas voltadas para a promoção da igualdade racial e a inclusão das minorias étnicas. Este é o papel desempenhado pela 6a Câmara de Coordenação e Revisão, "câmara temática populações indígenas e comunidades tradicionais".

Entende-se que a aproximação do MPF com a questão cigana ocorre, principalmente, graças à mobilização e interlocução de algumas referências "ciganas", que atuam, em maioria, como lideranças ou chefes de algum grupo de "ciganos" ou associações civis, reunidos especialmente em torno de vínculos familiares. O papel do MPF nesta pauta dá-se não tanto (ou apenas) pela natureza e atribuições do órgão, que prevê, em sua legislação orgânica, a atuação com povos e comunidades tradicionais, mas, sobretudo pelo trabalho de diversas pessoas "ciganas" que despertam a sensibilidade de pessoas como "Doutor Luciano Maia", que aparece na pesquisa de campo como um pioneiro no MPF, no aspecto humanitário, mas também outros procuradores mobilizados a 
"Nós somos os primeiros a serem acusados": um estudo sobre o "anticiganismo" e as... Phillipe Cupertino Salloum e Silva • Dr. Luiz Eduardo Figueira

atuarem em prol das comunidades "ciganas", em níveis regionais ou nacionalmente.

\begin{abstract}
Esse tema cigano tem uma autoria e é indiscutível que é Dr. Luciano Mariz Maia. É impressionante isso, mas, é uma coisa fora de discussão, eu entrei no MP, logo depois entrou o Dr. Luciano e acredito que foi um dos primeiros temas com os quais ele trabalhou. E aquilo que era local, Luciano conseguiu transformar cada vez mais em nacional (TV MPF, 2018).
\end{abstract}

É possível afirmar que, em alguns momentos, ao longo da sua história, no Brasil, o acesso dos "povos ciganos" a determinados territórios, dependeram da negociação e interlocução, com outras autoridades e entidades, com o objetivo de conquistar o direito de passagem e resistir às tentativas de sujeição e aniquilamento cultural. Todavia, estas interlocuções não significam que os "povos ciganos" dependam ou busquem, sempre, serem tutelados, mas, sim, que se trata de uns dos recursos estratégicos para sobreviver, individualmente, e enquanto coletividade "cigana".

A necessidade de uma pessoa, que se reconhecia e era identifica como "cigana" em apresentar um "salvo-conduto", há 20 anos atrás (meados da década de 1990), para circular dentro do território nacional, sendo "brasileira", reforçam a permanência no tratamento dos "ciganos" como intrusos, forasteiros ou estrangeiros. Sobretudo levando em consideração que a Constituição Federal, vigente desde 1988, que prevê como um preceito fundamental o direito de ir e vir, assim como a promoção do bem de todos, sem preconceitos de origem, raça, sexo, cor, idade e quaisquer outras formas de discriminação. Por outro lado, no imaginário social dos brasileiros permanece a ideia que os "ciganos" são pessoas que "vem de fora" ou que "não possuem um endereço fixo" (GOLDFARB, 2013), que não devem circular ou acessarem determinados espaços.

Interpreta-se o uso e a concessão de "salvo-condutos" para "ciganos", mesmo após a vigência da Constituição de 1988 ou do próprio advento dos princípios liberais nas constituições brasileiras, 
"Nós somos os primeiros a serem acusados": um estudo sobre o "anticiganismo" e as... Phillipe Cupertino Salloum e Silva • Dr. Luiz Eduardo Figueira

enquanto um aspecto do que Marilena Chauí chama de "cultura senhorial", um marco explicativo válido para a compreensão da vida em sociedade no Brasil. Além de ter sido estruturada a partir da matriz senhorial da Colônia, a autora destaca outro traço marcante da sociedade brasileira, o fato de ser constituída por meio das relações privadas.

Significa que as divisões sociais são naturalizadas em desigualdades postas como inferioridade natural e as diferenças, também naturalizadas, tendem a aparecer ora como desvios da norma (no caso das diferenças étnicas e de gênero), "permitindo a naturalização de todas as formas visíveis e invisíveis de violência, pois estas não são percebidas como tais" (CHAUÍ, 2000, p. 94). A estruturação da sociedade a partir da relações privadas quer dizer que são fundadas no mando e na obediência, disso decorre "a recusa tácita (e às vezes explícita) de operar com os direitos civis (...) as leis são necessariamente abstratas e aparecem como inócuas, inúteis ou incompreensíveis, feitas para ser transgredidas e não para ser cumpridas nem, muito menos, transformadas" (2000, p. 94-95).

Alguns interlocutores, pessoas e instituições são mobilizados pelos "ciganos" justamente para enfrentar o autoritarismo presente na sociedade brasileira, garantir, por exemplo, o direito fundamental de ir e vir. Ao mesmo tempo, esta mobilização de órgãos como o MPF se utiliza também de traços, práticas do que Chauí chama de "cultura senhorial", não enfrentando esta questão a fundo, isto é, o porquê de pessoas "ciganas", por sua condição étnica, para exercerem suas liberdades básicas, precisarem da intermediação de autoridades, para enfrentar abusos e coerções de outras autoridades. O que acontece àqueles "ciganos", que assim como Belchior diz na canção "apenas um rapaz latino-americano", for "sem dinheiro no banco, sem parentes importantes e vindo do interior"?

Franz Moonen compartilhou um trecho do jornal Diário da Borborema, de 1994, que noticia o fato de "um cigano mostrar também cartas de recomendação de prefeitos, deputados e até de um juiz, atestando sua honestidade" e que apesar de existir denúncias contra os "ciganos" veiculadas nas emissoras de rádio da 
"Nós somos os primeiros a serem acusados": um estudo sobre o "anticiganismo" e as... Phillipe Cupertino Salloum e Silva • Dr. Luiz Eduardo Figueira

cidade (Campina Grande), não havia nenhuma queixa formalizada na Central de polícia contra eles (2011, p. 159).

"Nós somos os primeiros a serem acusados", afirmou Maria Jane, militante "cigana", em maio de 2018, durante as atividades do IV CONAPIR, se referindo ao modo como os "ciganos" são tratados quando ocorre algum crime nas localidades onde passam. Ela não foi a única pessoa de quem ouvi esse tipo de relato, nas audiências públicas acompanhadas na pesquisa de campo. A interação entre os "ciganos" e a burocracia estatal não é recente, e muito menos harmônica.

O procurador Edmundo Dias destacou, durante a audiência da PGR, que "de um lado o estado que não consegue enxergar os povos, rom, sinti e calon 3, e outros povos ciganos que se colocam numa situação de invisibilidade porque o Estado quando os vê, em geral, é, se faz por meio dos mecanismos de repressão estatal" (TV MPF, 2018).

"A gente sofre muita perseguição policial, muitas ciganas apanham, as casas invadidas, crianças, é muito muito ruim" (TV SENADO, 2018), afirmou o Willamis, representante dos "ciganos" de Alagoas na audiência pública do Senado, em maio de 2018, ao narrar um episódio em que a polícia entrou num acampamento "cigano" sem mandato judicial para averiguar denúncias quanto a existência de armas e proferiu agressões aos "ciganos" independentemente da idade e do gênero.

Em todas as audiências públicas e espaços de interlocução com o Estado brasileiro, e por diferentes atores, "ciganos" ou não, são apontados e narrados episódios de discriminação, de anos atrás (período colonial), assim como mais recentes, envolvendo pessoas "ciganas" e, especialmente, a atuação policial.

Como será apresentado no próximo tópico, não são poucos os registros de como o sistema normativo, ao longo dos séculos, foi acionado para promover políticas de controle social aos "ciganos", combatendo suas expressões culturais, isto é, buscando extinguir seus conhecimentos, práticas e existência enquanto identidade 
"Nós somos os primeiros a serem acusados": um estudo sobre o "anticiganismo" e as... Phillipe Cupertino Salloum e Silva • Dr. Luiz Eduardo Figueira

étnica distinta. Tanto os registros do uso de "salvo-condutos", assim como as leis do período colonial são uma das principais fontes para se construir uma genealogia sobre como condição "cigana" foi gerida na Europa Ocidental e na sociedade brasileira.

\section{A Política Colonial}

A inserção dos "ciganos" no Brasil, assim como nos países colonizadores, foi marcada por mecanismos repressivos que ainda influenciam na definição de seu status jurídico-político. Tentar compreender como e quando teriam começado às perseguições aos "ciganos" e o porquê são questões relevantes para o objeto deste estudo. Como se trata de um povo, em geral, de cultura ágrafa, é a partir da sistematização dos documentos escritos emitidos por pessoas "não-ciganas", como as leis coloniais, que aqui se busca construir uma genealogia sobre a construção da condição "cigana" no Brasil.

Entre 1526 e 1761, aproximadamente vinte leis, alvarás ou cartas régias foram emitidas, visando, especificamente, as populações "ciganas". Por isso, cabe analisar as primeiras informações sobre os "ciganos", quando eles passaram a ser chamados como tais, a partir do século XV, marco temporal relacionado ao início da reivindicação da modernidade eurocentrada, que permanece mobilizando o "anticiganismo" e as classificações raciais, em geral, para se reinventar a partir de uma lógica individualista e excludente.

Segundo Angus Fraser (1992), desde o século XV a palavra "cigano", que deriva da palavra espanhola gitano, assim como a inglesa gypsy, é utilizada como um insulto. Há afirmações que indicam que o termo "cigano" teria sido "registrado pela primeira vez em português em 'A farsa das ciganas' de Gil Vicente" (TEXEIRA, 2008 , p. 9), em 1521. Na peça teatral "A farsa das ciganas" adota-se o uso da figura do "cigano" como tipo social novíssimo no reino (em 1526), não apenas para retratar os "ciganos", mas para 
"Nós somos os primeiros a serem acusados": um estudo sobre o "anticiganismo" e as... Phillipe Cupertino Salloum e Silva • Dr. Luiz Eduardo Figueira

abordar parodicamente as táticas da nobreza para se manter no poder, com casamentos endógenos, num enlace cultural fechado pela consanguinidade e pela barganha política (NORONHA, 2019).

Entretanto, o termo "cigano" apareceu em língua portuguesa antes deste ano, num poema palaciano de Luís da Silveira, intitulado "As Martas de D. Jerónimo" (RESENDE, 1852). O poema, publicado em 1516, com textos escritos desde 1449, atribuia o desaparecimento das peles de toupeira (martas) que encurtara as mangas do casaco de D. Jerônimo de Eça, a um "engano" promovido por um "Çiguano, ou muy fina feyticeira" (RESENDE, 1852, p.295-296). É importante dizer que a denominação "cigano", atribuída por pessoas "não ciganas", foram assumidas por estas pessoas nominadas "ciganas", obrigados a se identificarem às autoridades locais (GOLDFARB, 2013), embora "entre eles a denominação fosse calés (singular caló), e ainda rons ou rones" (RAMOS, 1947, p. 269, destaque dos autores).

Relaciona-se, neste estudo, a "questão cigana" no Brasil ao conceito de "colonialidade", pensado por Quijano (2002) como algo que transcende as particularidades do "colonialismo" histórico e que não desaparece com a independência ou descolonização. Essa proposta teórica é uma tentativa de compreender a modernidade como um processo intrinsecamente vinculado à experiência colonial. Essa diferença entre "colonialidade" e "colonialismo" possibilita, dessa forma, identificar e explicar as permanências nas formas coloniais de dominação, como a "raça", mesmo após o fim das administrações coloniais.

Segundo Aníbal Quijano, a história do poder colonial teve duas implicações decisivas para os povos, de alguma forma, colonizados. O grande número de diferentes povos, "cada um com sua própria história, linguagem, descobrimentos e produtos culturais, memória e identidade foram despojados de suas próprias e singulares identidades históricas" (2000, p. 9). A segunda implicação é, talvez, menos "óbvia, mas não é menos decisiva: sua nova identidade racial, colonial e negativa, implicava o despojo de seu lugar na história da produção cultural da humanidade. Daí em diante 
"Nós somos os primeiros a serem acusados": um estudo sobre o "anticiganismo" e as... Phillipe Cupertino Salloum e Silva • Dr. Luiz Eduardo Figueira

não seriam nada mais que raças inferiores, capazes somente de produzir culturas inferiores" (QUIJANO, 2005, p. 9).

Diante das continuidades nas formas coloniais de dominação, como o conceito de "colonialidade" propõe, lança-se o seguinte questionamento: é possível que a positivação de direitos reverta as consequências de anos de processos coloniais? Ou, nas palavras de Rita Segato:

[...] depois do longo processo de colonização europeia, o estabelecimento do padrão da colonialidade e o aprofundamento posterior da ordem moderna sob a condução das Repúblicas - muitas delas tanto ou mais cruéis que o próprio colonizador de ultramar - poderia agora, subitamente, o Estado retirar-se? (2011, p. 9).

Embora Quijano dê ênfase aos "índios" ou aos "povos trazidos forçadamente da futura África como escravo", aqui se destaca que os "ciganos" também foram e ainda estão inseridos nas formas coloniais de dominação, processo que é central para a constituição do Estado-nação, do Sistema de Justiça e das subjetividades estabelecidas como padrão na contemporaneidade. Para pesquisadora portuguesa Elisa Costa (2005), o papel do "povo cigano" enquanto elemento colonizador, por consequência, construtor do Brasil, não vem sendo tido na devida conta pela historiografia.

A partir da pesquisa de campo sobre a tramitação do Projeto de Lei do Senado n²48/2015, nota-se que episódios ou narrativas de expulsões, extermínios, matanças, difamações, calúnias ou injúrias envolvendo os "ciganos", por sua condição étnica-racial, não ficaram no passado. São uma realidade. Por isso, é possível afirmar, concordando com Marilena Chauí, que é um equívoco supor que o autoritarismo é "um fenômeno político que, periodicamente, afeta o Estado", pois, na verdade, a sociedade brasileira "é autoritária e que dela provêm as diversas manifestações do autoritarismo político" (2000, p. 94). Por outro lado, a mobilização da "questão cigana" pelo Estado brasileiro, nas últimas décadas, 
"Nós somos os primeiros a serem acusados": um estudo sobre o "anticiganismo" e as... Phillipe Cupertino Salloum e Silva • Dr. Luiz Eduardo Figueira

atrelado à retórica da inclusão social e de um país "multicultural", contribui para o fomento do que Chauí chama de "mito fundador".

Nas palavras Natasha Barbosa, representante do governo federal na pasta da promoção da igualdade racial, durante a audiência no Senado, em maio de 2018, "o sangue cigano corre nas veias de todos cidadãos da nossa nação" (TV SENADO, 2018b). A ideia de "nação brasileira" está permanentemente sendo constituída. E para isso, alguns mitos são construídos ou ressignificados, que no sentido antropológico, representam narrativas compostas "por soluções imaginárias para tensões, conflitos e contradições que não encontram caminhos para serem resolvidos no nível da realidade" (CHAUÍ: 2000, p. 5-6).

Natasha Barbosa: Nós temos que lembrar que desde então, os ciganos, os quilombolas, negros, todas essas comunidades estão em nosso sangue, então é um compromisso que eu acho que temos que ter para além das políticas públicas, ela tem que ser pessoal. (TV SENADO, 2018b)

Entende-se que a narrativa da "mistura harmônica de raças" e da "democracia racial", que vêm sendo mobilizada também a partir da "questão cigana", é um desses mitos. Para a autora Marilena Chauí, "fundação" se refere a um momento passado imaginário, tido como instante originário que se mantém vivo e presente no curso do tempo. É limitado falar que os "ciganos" apenas participaram da formação cultural do Brasil, por exemplo, pois remete a ideia de uma história propriamente dita, encerrada.

O "mito fundador" oferece um repertório inicial de representações da realidade e, em cada momento da formação histórica, esses elementos são reorganizados tanto do ponto de vista de sua hierarquia interna (isto é, qual o elemento principal que comanda os outros) como da ampliação de seu sentido (isto é, novos elementos vêm se acrescentar ao significado primitivo). Assim, as ideologias, que necessariamente acompanham o movimento histórico da formação, alimenta-se das representações produzi- 
"Nós somos os primeiros a serem acusados": um estudo sobre o "anticiganismo" e as... Phillipe Cupertino Salloum e Silva • Dr. Luiz Eduardo Figueira

das pela fundação, atualizando-as para adequá-las à nova quadra histórica. É exatamente por isso que, sob novas roupagens, o mito pode repetir-se indefinidamente (CHAUÍ, 2000, p. 7).

Parte-se do pressuposto que a "questão cigana" se iniciou desde as primeiras interações dos "ciganos" nos territórios brasileiros, contexto da colonização e que teve como marco inicial a diáspora, desde a Península Ibérica e especialmente de Portugal, assim como o nomadismo forçado dentro do próprio território brasileiro; e que permanece, até o presente momento, sob novas roupagens.

Hoje, no Brasil, há a pretensão de instituir um estatuto (lei ordinária) para os "ciganos", contudo esta proposta não é inédita, apenas sua finalidade humanitária. Não se pode esquecer que por séculos vigorou "Leis acerca dos Ciganos", como denomina os registros históricos das leis e ordenações emitidas no Reino de Portugal. Entre os séculos XVI e XVIII, foram produzidos em Portugal dezenas de alvarás, cartas régias e ofícios com a pretensão de administrar, controlar e exterminar os "ciganos" e a forma de vida a eles relacionados.

Registros apontam que a primeira onda "cigana" na Europa Ocidental, a partir dos anos iniciais do século XV, "aparentemente era composta por indivíduos relativamente bem comportados, cujos líderes se apresentavam não apenas com títulos de nobreza, mas também com nomes cristãos - André, Antônio, Francisco, Miguel, Thomás e outros" (MOONEN, 2011, p. 28). Por apresentarem nomes cristãos, "salvo-condutos" e cartas de apresentação (que correspondem, mais ou menos, aos passaportes da atualidade), emitidos por reis e papas, como o imperador católico Sigismundo (1410-1437) e do papa Martinho V (1417-1431), as pessoas reconhecidas como "ciganas" foram, inicialmente, bem recebidas pelas autoridades civis e eclesiásticas. Contudo, estes documentos deixaram "de ter valor, em toda a Europa Ocidental, a partir do final do século 16, e com eles desaparecem também - por serem agora inúteis - os líderes ciganos com reais ou falsos títulos de nobreza" (MOONEN, 2011, p. 31). 
"Nós somos os primeiros a serem acusados": um estudo sobre o "anticiganismo" e as... Phillipe Cupertino Salloum e Silva • Dr. Luiz Eduardo Figueira

As primeiras referências aos "ciganos" em Portugal aparecem no final do século XV e logo começa também a perseguição a eles, sendo que em 1526 em diante foi proibida a entrada desta população e decretada a expulsão, entre outras penalidades, daqueles que já se encontravam no país, sendo o Brasil um dos destinos para o degredo (COSTA, 2005).

Segundo a estudiosa portuguesa Elisa Costa, no artigo "Contributos ciganos para o povoamento do Brasil (séculos XVIXIX)", é possível afirmar que as punições aos "ciganos" começaram desde cedo. A autora pondera que se está diante de um povo de cultura ágrafa, oral, e que não há documentos escritos pelos próprios "ciganos", por isso a legislação específica produzida no decurso do tempo em Portugal, semelhantes a outros sistemas normativos no continente europeu, é a única fonte com carácter sistemático disponível.

Percebe-se que a maioria das "faltas que Ihes foram imputados são tão-somente formas de expressão da sua cultura e tradições, cuja perpetuação em nada tinha a ver (conforme ainda hoje sucede) com a área geográfica em que estavam a viver" (COSTA, 2005, p. 154).

Por exemplo, a "Lei de 28 de Agosto de 1592" estabelecia penas aos "ciganos" que, dentro de 4 meses não saíssem de Portugal ou "se não se avizanhassem nos Lugares sem andarem vagabundos, não podem andar, nem estar ou viver mais em ranchos, ou Quadrilhas, tudo sob pena de morte natural".

A "Lei de 24 de Outubro de 1647" proibia que os "ciganos":

[...] que não falem Girigonça, nem ensinem a seus filhos, nem andem em trages de Ciganos; e serão obrigados a trabalhar, em quanto poderem, como fazem os naturaes do Reino; e estando impossibilitados por doença, ou muita idade, se Ihes permitirá poderem pedir esmolas nos mesmos Lugares em que viverem, sem que possam usar de suas traças e embustes, a que chamam de buenas dichas, e jogos de corriola, nem partidos de cavalgaduras. (FREITAS, 1819, p. 364). 
"Nós somos os primeiros a serem acusados": um estudo sobre o "anticiganismo" e as... Phillipe Cupertino Salloum e Silva • Dr. Luiz Eduardo Figueira

Em 24 de maio de 2019, durante evento de comemoração ao "Dia Nacional do Cigano", organizado pelo governo federal, em parceria ao MPF, Aline Miklos, que se identifica e é identificada como "cigana" kalderash, pesquisadora em história da arte, afirmou que ao longo da colonização do Brasil, três condutas, associadas aos ciganos, foram tipificadas enquanto crimes: andar/morar em grupo, falar a própria língua ou vestir-se de forma diferente do padrão. "Urgia mudar os comportamentos sociais diferenciadores a fim de tornar os ciganos iguais à restante população" (COSTA, 2005, p. 155). Conforme destacou esta autora, as legislações específicas no período colonial tinham como alvo:

[...] a itinerância praticada sempre em grupo (e, ao atraírem gentes não-ciganas causavam ainda mais temor logo, eram vistos como uma ameaça redobrada), vestirem traje de ciganos (ou seja de maneira diferente), conversarem na sua própria língua, designada por geringonça nos documentos (trata-se do dialecto caló, falado na Península Ibérica, sendo a língua denominada romani), a leitura da sina pelas mulheres. (COSTA, 2005, p. 155).

Embora os documentos oficiais portugueses, a partir do século XVI, ordenassem aos ciganos saírem do país, estes não tinham para onde fugir, pois Portugal só tem limites terrestres com a Espanha, onde também eram perseguidos. Por essa razão, a partir de 1649, foram intensificadas as ordens de deportação dos "ciganos" em direção às colônias ultramarinas. Contudo, parece que estas medidas tiveram pouca eficácia, pois, em 1694, outro documento emitido pelo rei informa "que os ciganos nascidos neste Reino continuam em seu usos e delitos, sem tomarem gênero de vida nem ofício de possam sustentar-se, vivendo arranchados e juntos em quadrilhas, trazendo os mesmos hábitos e trajes de ciganos, sem terem domicílio certo ..." (COELHO, 1995, p. 219-220).

Ao contrário da Espanha e de outros países europeus que previam a pena de morte, Portugal parece ter evitado ao máximo a 
"Nós somos os primeiros a serem acusados": um estudo sobre o "anticiganismo" e as... Phillipe Cupertino Salloum e Silva • Dr. Luiz Eduardo Figueira

aplicação desta pena, embora estivesse prevista, preferindo o banimento dos "ciganos" para suas colônias ultramarinas (MOONEN, 2011), o que não deixa de ser cruel pois se tratava um caminho sem volta, em que famílias, casais, filhos erram separados.

Para Bill M. Donovan, "talvez a mais severa repressão tenha ocorrido em Portugal, onde a coroa tentou sistematicamente cercar e banir famílias "ciganas" para colônias estrangeiras na África e na América" (1992, p. 33). Este autor argumenta que as condições sociais e econômicas do Brasil colonial mudaram as categorizações portuguesas de "ciganos" como desviantes sociais, as fronteiras sociais passaram a ser fundamentalmente alteradas na colônia, pois os escravos africanos deslocavam os "ciganos" como o estrato mais marginalizado e mais perigoso da sociedade luso-brasileira.

É quase certo que as primeiras pessoas que eram identificadas e que se identificavam como "ciganas" desembarcaram no Brasil, a partir do século XVI, foram oriundas de Portugal, são da etnia calon e não vieram voluntariamente, mas degredadas. Em 1574, há registros que João Torres e Angelina foram deportados para o Brasil, como parte da condenação pelo fato de serem "ciganos" (COELHO, 1995). Embora sejam sempre citados como os primeiros "ciganos" a entrarem no Brasil, como reproduz as cartilhas sobre políticas públicas, textos acadêmicos e na maioria das falas que ocorreram durante as audiências públicas e demais eventos sobre os "direitos dos ciganos", Franz Moonen (2011) pondera que não se sabe realmente se eles embarcaram, se sobreviveram a viagem e chegaram ao seu destino.

"Estamos aqui há 444 anos" (TV SENADO, 2018b), afirmou a militante "cigana" Maura Piomonte durante a audiência pública realizada no Comissão de Direitos Humanos do Senado, em 28 de maio de 2018, fazendo referência ao ano de 1574. Na mesma ocasião, Natasha Barbosa, representante da Secretaria de Promoção da Igualdade Racial no governo de Michel Temer, sustentou que "muito antes de 1574, como seja mencionado, em 1534 eles já estavam aqui, e isso foi o primeiro registro de um jesuíta falando sobre os ciganos aqui" (TV SENADO, 2018b). 
"Nós somos os primeiros a serem acusados": um estudo sobre o "anticiganismo" e as... Phillipe Cupertino Salloum e Silva • Dr. Luiz Eduardo Figueira

As dúvidas quanto à veracidade destas informações, assim como a falta de consenso em relação aos dados, como um todo, são parte das estratégias por sobrevivência e resistência "cigana". Esta imprecisão faz parte, inclusive, da própria delimitação da identidade "cigana". Principalmente por ser um povo de cultura oral, ágrafo, as narrativas e os processos sociais que envolvem os "ciganos" são tão importantes quanto a própria exatidão nos dados e na historiografia.

Fazer referência a João Torres como o primeiro "cigano" a entrar no Brasil, em 1574, ou qualquer outra data mais antiga, é comum entre as narrativas que abordam a importância dos "ciganos" no processo de construção do Brasil. Todavia, com base nas leis coloniais produzidas entre o século XVI e XVIII, a deportação em massa de "ciganos" portugueses para o Brasil, provavelmente, se iniciou - ou se intensificou - a partir de 1686, pois, nesse ano houve dois documentos emitidos pelo rei de Portugal informando que os "ciganos" deviam ser degradados para o Maranhão.

É possível afirmar que a construção jurídico-política da condição "cigana" no Brasil obviamente foi e ainda é influenciada por representações negativas que induzem uma permanente desconfiança em relação a população "cigana", pois são recorrentes as narrativas relacionando a vivência "cigana" a episódios de violência e discriminação.

A delimitação da identidade do colonizador, ser civilizado, sedentário, associado à condição branca, precisou ser construída em contraposição a outras identidades, tratadas como naturalmente inferiores, "a codificação das diferenças entre conquistadores e conquistados na ideia de raça, ou seja, uma supostamente distinta estrutura biológica que situava a uns em situação natural de inferioridade em relação a outros" (QUIJANO, 2005, p. 227).

Uma diversidade de culturas e identidades presentes nos continentes hoje conhecidos como "África" ou "América" foram reduzidos a uma única identidade, respectivamente, negros e índios; da mesma forma as pessoas conhecidas como "ciganas". 
"Nós somos os primeiros a serem acusados": um estudo sobre o "anticiganismo" e as... Phillipe Cupertino Salloum e Silva • Dr. Luiz Eduardo Figueira

Segundo Quijano (2005), na América, a ideia de raça foi uma maneira de outorgar legitimidade às relações de dominação impostas pela conquista. Nem sempre existiu "Europa" ou "América". São categorias simbólicas, criadas e adotadas a partir do século XV. A constituição da "Europa" como nova identidade ocorreu depois da "América" e a expansão do colonialismo europeu que conduziram à elaboração da perspectiva eurocêntrica do conhecimento e com ela à elaboração teórica da ideia de "raça" como naturalização dessas relações coloniais de dominação entre europeus e não-europeus.

"Desse modo, a raça converteu-se no primeiro critério fundamental para a distribuição da população mundial nos níveis, lugares e papéis na estrutura de poder da nova sociedade. Em outras palavras, no modo básico de classificação social universal da população mundial" (QUIJANO, 2005, p. 228).

A colonização dos territórios hoje conhecidos como "América" ou "África", a partir do século XV, não significou apenas a invasão de territórios e a sua exploração econômica. Para a história da humanidade, o colonialismo eurocêntrico representa o maior processo de tortura, genocídio e etnocídio que ocorreu no mundo; atingiu, de forma distinta, os mais diversos territórios e grupos populacionais subjugados e classificados racialmente como inferiores (índios, negros, ciganos etc), como também diferentemente os homens e as mulheres.

Os alvarás e outros documentos de natureza normativa emitidos pelo rei português e demais autoridades cujas as atuações influenciaram na gestão do território brasileiro revelam fortes indícios que a colonização perpassou também sobre o controle dos corpos das mulheres "ciganas", assim como ocorreu com as demais mulheres, especialmente as não-brancas. Há diferentes leis produzidas a partir do século XVI que previam punições e tratamentos distintos aos homens e mulheres "ciganas".

A "Lei de 28 de Agosto de 1592", que, além de impor a pena de morte (punição renovada mais uma vez, em 1694) aos "ciganos" que infringissem as medidas integradoras nela contidas, ou em 
"Nós somos os primeiros a serem acusados": um estudo sobre o "anticiganismo" e as... Phillipe Cupertino Salloum e Silva • Dr. Luiz Eduardo Figueira

alternativa, não abandonassem o país num máximo de quatro meses, estipulava que:

[...] as mulheres dos ciganos que estiverem presos nas galés que estão no porto desta cidade [Lisboa], ou em qualquer outro deste Reino em que estiverem, se sairão dele dentro dos ditos quatro meses, ou se avizinharão no Reino pela maneira acima declarada, deixando o dito hábito e língua dos ciganos: e não o fazendo assim serão publicamente açoitadas com baraço e pregão, e degredadas para sempre para o Brasil (SIMÕES, 1990).

A citação acima registra que as mulheres "ciganas" eram visadas de forma específica na "Lei de 28 de Agosto de 1592", previam punições a estas devido à circunstância dos respectivos maridos estarem cumprindo pena de prisão. Ou seja, eram punidas simplesmente por ser mulheres e por serem "ciganas".

Em outro documento de natureza normativa, emitido por Portugal, em 1708, o então rei, mais uma vez, ordenou que os homens "ciganos" fossem presos em galés e as mulheres "ciganas" fossem degredadas para o Brasil, ambos por dez anos.

Hey por bem, e mando que não haja neste Reyno pessoa alguma de um, ou de outro sexo, que use de trage, lingua, ou Giringonça de Ciganos, nem de impostura das suas chamadas buenas dichas [...] incorrerá na pena de açoutes, e será degradado por tempo de dez annos: o qual degredo para os homens será de galés, e para as mulheres, para o Brasil. (FREITAS, 1819, p. 364).

A referida lei não punia apenas as pessoas "ciganas" que não corrigissem o seu modus vivendi, objeto direto de criminalização, mas, também abrangia "todos quantos não o sendo se juntassem" aos "ciganos", ou seja, "outros homens, e mulheres de ruim vida, que se lhes agregão, fação com elles escandalosa vida".

Segundo Elisa Costa, o agravamento das penas, que foi acontecendo a partir do século 16 adiante, tinha relação direta com a 
"Nós somos os primeiros a serem acusados": um estudo sobre o "anticiganismo" e as... Phillipe Cupertino Salloum e Silva • Dr. Luiz Eduardo Figueira

sua condição de insubmissos. Preconizou-se, em especial, a separação das famílias, tudo o indica com a intenção de os exterminar apesar de tal não estar explícito nos textos do corpus legislativo, excepção feita às duas leis que lhes impuseram a pena máxima. A integração a ser preterida em favor da exclusão e, de certa maneira, da reclusão eis como pode ser caracterizado este período (COSTA, 2005, p. 156).

O "modo de vida cigano" era, portanto, associado, visto como práticas sociais desviantes, tipificado como conduta criminosa, objeto de punição, do controle externo, "como tudo aquilo que não devemos ser". As leis do período colonial não buscavam, portanto, apenas determinar como os "ciganos" e as "ciganas" deveriam se comportar para serem aceitos, mas, acima de tudo definir qual comportamento padrão que deveria ser seguido na sociedade.

Por exemplo, o “Alvará régio de 20 de Setembro de 1760" impôs aos homens "ciganos" o trabalho como soldados ou em obras públicas e que as mulheres "ciganas" deveriam viver recolhidas em casa e se ocupar dos mesmos ofícios que seus pais. As políticas "anticiganas" pretendiam regular os comportamentos da generalidade das pessoas punidas com tal condenação. Além disso, é possível deduzir que muitas mulheres "ciganas", não todas, foram deportadas para o Brasil com fins reprodutivos, como parte do projeto colonizador, vivenciaram uma dupla opressão, como os homens "ciganos", por conta da sua condição étnica, e por serem mulheres.

China (1936) buscou sintetizar uma série de reportagens e entrevistas sobre os "ciganos" no início do século XX e compartilhou em seu artigo a resposta do jornalista Mário Torres sobre os “ciganos" da Bahia afirmando serem ladrões profissionais, mentirosos, e interpreta como uma anormalidade o fato das mulheres quando viajam a cavalo, montarem como os homens, enganchadas, e que quando dão a luz, continuarem seus trabalhos como se nada houvesse acontecido.

Se é possível afirmar que, em diferentes sociedades, havia hierarquia e relações de gênero como relações de poder e prestígio 
"Nós somos os primeiros a serem acusados": um estudo sobre o "anticiganismo" e as... Phillipe Cupertino Salloum e Silva • Dr. Luiz Eduardo Figueira

desigual "com a intervenção colonial estatal e a imposição da ordem da colonial / modernidade, essa distância opressiva se agrava e amplifica. Ocorre uma mutação sob o manto de uma aparente continuidade" (SEGATO, 2003, p. 25).

A normatividade rígida de gênero, centrada na reprodução e na domesticidade e feita como ideal civilizatório contra os males de uma interação "desviante" em termos de gênero e sexualidade, como se buscou com as leis coloniais visando as mulheres "ciganas", faz parte do arsenal racista da "colonialidade" e, uma vez imposta como ideal e parâmetro de relações, modifica as conformações das formas de relações entre os colonizados, reforçando estruturas e hierarquias de gênero que tinham outras dinâmicas (SEGATO, 2003).

A presença das mulheres que se identificam e são identificadas enquanto "ciganas" em ambientes públicos, como se dá na tramitação do PLS n 248/2015 e realizando funções econômicas e política autônomas, práticas historicamente associadas aos homens, vão de encontro às normativas sociais que delimitam os papéis a serem cumpridos pelos homens e pelas mulheres. Inclusive desmistifica a construção que se dá nos imaginários sociais de que as mulheres "ciganas" cumprem apenas papéis submissos ou secundários em suas respectivas famílias, ao mesmo tempo, que são consideradas agressivas quando circulam em ambientes externos, igualmente perigosas, como os homens "ciganos" são tratados.

Os preconceitos e estereótipos racistas e ciganofóbicos aos quais essas mulheres são submetidas são sempre produzidos por marcas de gênero e por conotações fortemente sexualizadas (REA, 2017). As representações "cigana misteriosa" e "feiticeira" podem ser percebidas na emblemática expressão "olhos de cigana oblíqua e dissimulada" (1994, p. 32), descrição de Machado de Assis sobre a Capitu, personagem de Dom Casmurro, uma das obras mais influentes da literatura brasileira, escrita no final do século XIX. Capitu, assim como as idealizações sobre as mulheres "ciganas", é o oposto da mulher frágil, previsível e inocente, características que ainda buscam definir os padrões femininos no contexto atual. 
"Nós somos os primeiros a serem acusados": um estudo sobre o "anticiganismo" e as... Phillipe Cupertino Salloum e Silva • Dr. Luiz Eduardo Figueira

Não é possível mensurar, exatamente, em que medida foram eficazes as diversas leis, alvarás, cartas régias, visando especificamente a população "cigana", promulgadas ao longo dos séculos, que visavam tanto os homens como as mulheres. Leis que previam medidas distintas para os homens e as mulheres "ciganas".

Embora não estivesse explícito nos textos das leis e ordenações, o objetivo dessa produção intensa produção legislativa era separar as famílias "ciganas", assim como criminalizar, mudar e extinguir os comportamentos associados aos "povos ciganos" no Brasil, assim como nos demais territórios colonizados por Portugal. Não apenas os "ciganos", mas aqueles ou aquelas pessoas que se unissem ou manifestassem traços comportamentais "ciganos" também foram alvos do controle social nas leis do período colonial.

Por outro lado, a presença de famílias ciganas em quase todos estados e em diversos municípios brasileiros confirma que houve um permanente processo de resistência, que as políticas "anticiganas" do período colonial não foram plenamente eficazes, mas certamente produziram efeitos determinantes na delimitação das identidades e representações ciganas. Após a independência ou com o advento das ideais liberais-republicanas no Brasil, não cessaram as políticas "anticiganas", pelo contrário, se reinventaram, a partir de novas roupagens, como são percebidos nos registros jornalísticos e nas obras científicas sobre os "povos ciganos" século XIX em diante.

\section{Considerações Finais}

A reivindicação por políticas públicas e ações distintas, visando a inclusão social dos "ciganos", nas últimas décadas, podem revelar duas sínteses. A emergência da pauta "cigana", na agenda governamental, vem aproximando este segmento étnico do aparato estatal, de natureza humanitária, ou seja, não mais restritos aos aparelhos repressivos, como ocorreu no passado. Todavia, 
"Nós somos os primeiros a serem acusados": um estudo sobre o "anticiganismo" e as... Phillipe Cupertino Salloum e Silva • Dr. Luiz Eduardo Figueira

a necessidade de uma intervenção estatal, como está sinalizado na proposta do PLS n' 248/2015, que pretende criar o "Estatuto Cigano", indica que a sociedade brasileira não se desassociou, plenamente, do passado colonial e das classificações raciais advindas deste período, que geram o "anticiganismo" e a exclusão social.

A concessão de um "salvo-conduto", para permitir a passagem de pessoas brasileiras e "ciganas", dentro do território nacional, em um contexto pós Constituição Federal de 1988, repete uma estratégia antiga: a proteção de autoridades (ou a simulação deste apoio) para se obter o direito de ir e vir. Porém, não se pode cair em anacronismos, pois, as primeiras interações entre as sociedades majoritárias e as pessoas classificadas e que se identificavam como "ciganas" ainda ocorriam em meio ao desconhecimento. Diferente de agora, em que se trata de um segmento étnico amplamente reconhecido (empiricamente ou no imaginário social), embora rejeitados e ainda tratados como invasores.

Diferente dos séculos $X V$ e XVI, vive-se no contexto do direito moderno, pautado por normas gerais e abstratas. A mobilização do "salvo-conduto", como foi exposta em duas audiências públicas do MPF, na contemporaneidade, aponta para a porosidade e fluidez das práticas estatais, que caminham entre o formal e o informal, mas também indica o não acesso dos "ciganos" aos legados civilizatórios advindos com as revoluções liberais, como a igualdade e a liberdade. Por isso, é reivindicado a intervenção estatal com fins humanitários.

Percebe-se, assim, que há uma ressignificação dos marcadores sociais, pautados a partir da "raça", que foram tecidos, ao longo dos séculos, e que contribuíram (assim como contribuem) para a fundação social, cultural e econômica do Brasil, enquanto nação. Foram dezenas de atos normativos, emitidos a partir da Coroa portuguesa, entre os séculos XVI e XVIII, visando, especificamente os "ciganos". Criminalizava-se não apenas o sujeito "cigano", mas, sobretudo, a forma de viver associada aos "ciganos", ou seja, as vestimentas, a linguagem, a moradia a sua organização social. 
"Nós somos os primeiros a serem acusados": um estudo sobre o "anticiganismo" e as... Phillipe Cupertino Salloum e Silva • Dr. Luiz Eduardo Figueira

A obsessão em relação aos "ciganos", como ocorreu no período colonial, foi reificada a partir de novas bases, se dissipando nas práticas sociais, que não demandam, necessariamente, de apareIhos repressivos estatais ou normas específicas para se manifestar. Neste sentido, as reflexões decoloniais, intercaladas aos estudos ciganos, podem ser uma chave para compreender o fenômeno do "anticiganismo" na sociedade, assim como nas práticas estatais. Conclui-se este artigo afirmando que a presença "cigana" no Brasil, ou em diferentes partes do mundo, possui um significado: trata-se de um povo em permanente processo de resistência e resiliência.

\section{Referências}

BRASIL. Decreto $n^{\circ} 1.983$, de 14 de agosto de 1996. Diário Oficial [da] República Federativa do Brasil. Brasília, 1996. Disponível em: < http://www.planalto.gov.br/ccivil_03/decreto/1996/D1983. htm>. Acesso em: 19 out. 2019.

BRASIL. Decreto $n^{\circ}$ 5978, de 4 de dezembro de 2006. Diário Oficial [da] República Federativa do Brasil, Poder Executivo, Brasília, DF, 2006b. Disponível em: <http://www.planalto.gov.br/ ccivil_03/_Ato2004-2006/2006/Decreto/D5978.htm>. Acesso em: 27 out. 2019.

CHAUÍ, Marilena. Brasil: mito fundador e sociedade autoritária. São Paulo: Fundação Perseu Abramo, 2000.

CHINA, J. de Oliveira. Os ciganos do Brasil. Revista do Museu Paulista, São Paulo, tomo XXI, 1936. p. 323-669.

COELHO, A. Os ciganos de Portugal. Lisboa: Dom Quixote, 1995. COSTA, Elisa Maria Lopes da. Contributos ciganos para o povoamento do Brasil (séculos XVI - XIX). Arquipélago - Revista da Universidade de Açoures, Açoures, v. 9-10, 2005. 
"Nós somos os primeiros a serem acusados": um estudo sobre o "anticiganismo" e as... Phillipe Cupertino Salloum e Silva • Dr. Luiz Eduardo Figueira

DAS, Veena; POOLE, Deborah. El Estado y sus márgenes. Etnografias comparadas. Cuadernos de Antropologia Social, Buenos Aires, n.27, p. 19-52, 2008.

DONOVAN, Bill M. Changing perceptions of social deviance: Gypsies in early modern Portugal and Brazil. Journal of Social History, s.l., 1992.

FOUCAULT, Michel. Microfísica do Poder. Rio de Janeiro: Graal, 2012.

FRASER, Angus. The Gypsies. Oxford: Blackwell Publishers, 1992.

FREITAS, Joaquim Ignacio de. Collecção chronologica de Leis extravagantes, posteriores a'nova compilação das ordenações do reino, publicadas em 1603. Coimbra, 1819.

GOLDFARB, Maria Patrícia Lopes. Memória e etnicidade entre os Ciganos Calon em Sousa-PB. João Pessoa: Editora da UFPB, 2013.

MPF. Discriminação e preconceito são rotina enfrentada por ciganos na Paraíba. Ministério Público Federal, 2017. Disponível em: <http://www.mpf.mp.br/pb/sala-de-imprensa/noticias-pb/ discriminacao-e-preconceito-sao-rotina-enfrentada-por-ciganos-na-paraiba>. Acesso em: 11 fev. 2020.

MOONEN, Frans. Anticiganismo: os ciganos na Europa e no Brasil. 3. ed. Recife: [s/e], 2011. Disponível em: < http://www. dhnet.org.br/direitos/sos/ciganos/a_pdf/1_fmanticiganismo2011. pdf>. Acesso em: 27 out. 2019.

NORONHA, Gilberto Cézar de. Os gadjós são os “perfeitos ciganos, muito ciganos": figurações, estereótipos e artimanhas políticas em Minas Gerais. In: ANPUH-Brasil - $30^{\circ}$ Simpósio Nacional de História, Recife, 2019.

QUIJANO, A. Colonialidade, Poder, Globalização e Democracia. Revista Novos Rumos, São Paulo, ano 17, n. 37, p. 4-28, 2002. 
"Nós somos os primeiros a serem acusados": um estudo sobre o "anticiganismo" e as... Phillipe Cupertino Salloum e Silva • Dr. Luiz Eduardo Figueira

QUIJANO, A. Colonialidade do poder, eurocentrismo e América Latina. In: A colonialidade do saber: eurocentrismo e ciências sociais: perspectivas latino-americanas. Buenos Aires: CLACSO, 2005.

RAMOS, Arthur. Introdução à antropologia brasileira. V. 4. As culturas europeias. Rio de Janeiro: Casa do Estudante do Brasil, 1947.

REA, Caterina Alessandra. Redefinindo as fronteiras do póscoIonial. O feminismo cigano no século XXI. Estudos Feministas, Florianópolis, v. 25, n. 1, fev. 2017. p. 31-50.

RESENDE, Garcia de. Cancioneiro Geral. Stuttgart Gedruckt auf Kosten des litterarischen Vereins, 1852.

SEGATO, Rita. La argamasa jerárquica: violencia moral, reproducción del mundo y la eficacia simbólica del derecho. In: Las estructuras elementales de la violencia. Ensayos sobre género entre la antropología, el psicoanálisis y los derechos humanos. Buenos Aires: Universidad Nacional de Quilmes/Prometeo, 2003. p. 107-130.

SEGATO, Rita. Género y colonialidad: en busca de claves de lectura y de um vocabulario estratégico descolonial. In: K. Bidaseca \& V. V. LABA (Eds.), Feminisimos y Poscolonialidad. Descolonizando el feminismo desde y en América Latina. Buenos Aires: Godot, 2011.

SIMÕES, Maria Alzira Proença (Org.). Catálogo dos impressos de tipografia portuguesa do século XVI. Lisboa: Biblioteca Nacional, 1990.

TEXEIRA, Rodrigo Corrêa. História dos ciganos no Brasil. Recife: Núcleo de Estudos Ciganos, 2008

TV MPF. Audiência Pública Maio Cigano 28/05/2018. 2018. (3h45m56s). Disponível: <http://www.tvmpf.mpf.mp.br/videos/2836>. Acesso em: 23 fev. 2018. 
"Nós somos os primeiros a serem acusados": um estudo sobre o "anticiganismo" e as... Phillipe Cupertino Salloum e Silva • Dr. Luiz Eduardo Figueira

TV SENADO. Estatuto do Cigano. 2018. (2h09m12s). 2018.

Disponível em: < https://www.youtube.com/watch?v=SCzeao1ZUn4\&t=4337s $>$. Acesso em: 18 out. 2019.

WAGNER, Francis S. The Gypsy Problem in Postwar Hungary. Hungarian Studies Review, v. XIV, n. 1, 1987. 